\title{
Association of Metabolic Syndrome and Its Components with Survival of Older Adults
}

\author{
Ali Bijani (iD ${ }^{1}$, Seyed Reza Hosseini (iD ${ }^{1}$, Reza Ghadimi (iD) ${ }^{1}$ and Simin Mouodi (iD) ${ }^{1,}$ \\ ${ }^{1}$ Social Determinants of Health Research Center, Health Research Institute, Babol University of Medical Sciences, Babol, Iran \\ "Corresponding author: Social Determinants of Health Research Center, Health Research Institute, Babol University of Medical Sciences, Babol, Iran. Email: \\ dr.mouodi@gmail.com
}

Received 2019 March 27; Revised 2020 January 13; Accepted 2020 January 14.

\begin{abstract}
Background: Metabolic syndrome (MetS) as an important risk factor arising from insulin resistance accompanying abnormal adipose deposition and function has become a major challenge to public health around the world.

Objectives: This research was conducted to evaluate the association of MetS and its components with survival of older adults.

Methods: This prospective study is a part of the Amirkola Health and Ageing Cohort Project (2011 - 2017) conducted among 1562 older adults (aged 60 years and over) living in Amirkola, north of Iran. MetS was defined according to four sets of definition: Iranian definition, International Diabetes Federation (IDF) definition, 2001 Adult Treatment Panel (ATP) III and 2005 Adult Treatment Panel (ATP) III.

Results: Eight hundred sixty-three (55.2\%) males and 699 (44.8\%) females with a mean age of $69.3 \pm 7.4$ years were included in the research. The results showed that 71.9\%, 74.3\%, 68.8\% and 66.7\% of older adults had MetS based on 2005 ATP III, Iranian, IDF and 2001 ATP III diagnostic criteria, respectively. Only raised fasting plasma glucose (FPG) had a significant association with a five-year survival rate of older adults (FPG $\geq 110 \mathrm{mg} / \mathrm{dL}$ : adjusted HR: 2.05; 95\% CI:1.51 - 2.78; P < 0.001). Other MetS components did not show any significant associations with survival $(\mathrm{P}>0.05)$. Nevertheless, MetS itself significantly decreased the survival rate of older adults after adjusting age, gender and number of chronic diseases ( $\mathrm{HR}=1.67 ; 95 \% \mathrm{CI}: 1.16-2.41 ; \mathrm{P}=0.006)$.

Conclusions: MetS and one of its components, high FPG, have significant associations with survival of older adults.
\end{abstract}

Keywords: Age, Metabolic Syndrome, Survival

\section{Background}

Metabolic syndrome (MetS) which is characterized by insulin resistance, hypertension, hyperlipidemia and abdominal obesity is a common health problem in older adults (1). The prevalence of MetS increases with age (2,3). Previous studies demonstrated different impacts of MetS on health outcomes. For example, in some studies, it was shown that MetS could be associated with higher morbidity and mortality of cardiovascular diseases, functional dependence and poorer quality of life in the elderly (4). Some other studies represented the positive impact of Mets on survival benefits (5). The overall risk estimate of all-cause mortality for MetS was reported 1.17 (1.07-1.28) (6).

Incidence of MetS increases with age (1); it is estimated that about one-third of US adults (1) and 55\% of adult population aged 60 and over have MetS (2). In Asian countries, the prevalence of MetS was ranged from $10 \%$ to $20 \%$ (7). In Iranian population, however, the overall weighted prevalence of this syndrome was reported 31\% (95\% CI: 28 - 35)
(8). The rate of MetS was ranged from $10 \%$ to $60 \%$, depending on sex, age and region (9).

\section{Objectives}

To improve survival rate in older adults and considering the importance of MetS components in prevention and control of their health-related outcomes $(6,10,11)$, this study was conducted to evaluate the association of MetS and its components with survival of older adults.

\section{Methods}

This prospective study was conducted based on data related to the Amirkola Health and Ageing Cohort Project (AHAP) $(12,13)$. Totally, 2234 people aged 60 years and over live in Amirkola, north of Iran. The entire population was 
invited to participate in the research, of whom 1616 individuals agreed to participate. For diagnosis of MetS, the subjects were invited for examination, but only 1562 individuals completed the examination. All the individuals were followed for 60 months to determine their vital or death status. The five-year survival rate and some related factors such as age, gender, and any of 25 chronic diseases (including cardiovascular, neurologic, psychological, renal, and hepatic disorders) have been assessed.

Metabolic syndrome was defined according to four sets of definition: Iranian definition (14), International Diabetes Federation (IDF) definition (15), 2001 Adult Treatment Panel (ATP) III (16) and 2005 Adult Treatment Panel (ATP) III (17). These four diagnostic sets are summarized in Table 1.

\begin{tabular}{|c|c|}
\hline Diagnostic Criteria & Measures and Categorical Cut-Off Points \\
\hline & $\begin{array}{l}\text { Raised serum triglyceride }(\geq 150 \mathrm{mg} / \mathrm{dL}), \\
\text { reduced } \mathrm{HDL} \text { cholesterol }(<40 \mathrm{mg} / \mathrm{dL} \text { in male } \\
\text { and }<50 \mathrm{mg} / \mathrm{dL} \text { in female), and raised blood } \\
\text { pressure (systolic } \mathrm{BP} \geq 130 \text { and/or diastolic } \mathrm{BP} \geq \\
85 \mathrm{mmHg} \text { ) in addition to central obesity and } \\
\text { previously diagnosed type } 2 \text { diabetes or raised } \\
\text { fasting plasma glucose (FPG), as below: }\end{array}$ \\
\hline $\begin{array}{l}2005 \text { Adult Treatment } \\
\text { Panel (ATP) III }\end{array}$ & $\begin{array}{l}\text { Waist circumference: male } \geq 102 \mathrm{~cm} \text { and female } \\
\geq 88 \mathrm{~cm} \text { with FPG } \geq 100 \mathrm{mg} / \mathrm{dL}\end{array}$ \\
\hline $\begin{array}{l}\text { 2001 Adult Treatment } \\
\text { Panel (ATP) III }\end{array}$ & $\begin{array}{l}\text { Waist circumference: male } \geq 102 \mathrm{~cm} \text { and female } \\
\geq 88 \mathrm{~cm} \text { with FPG } \geq 110 \mathrm{mg} / \mathrm{dL}\end{array}$ \\
\hline $\begin{array}{l}\text { International } \\
\text { Diabetes Federation } \\
\text { (IDF) definition }\end{array}$ & $\begin{array}{l}\text { Waist circumference: male } \geq 94 \mathrm{~cm} \text { and female } \\
\geq 80 \mathrm{~cm} \text { with } \mathrm{FPG} \geq 100 \mathrm{mg} / \mathrm{dL}\end{array}$ \\
\hline Iranian definition & $\begin{array}{l}\text { Waist circumference } \geq 95 \mathrm{~cm} \text { for male and } \\
\text { female with FPG } \geq 100 \mathrm{mg} / \mathrm{dL}\end{array}$ \\
\hline
\end{tabular}

To assess mortality rate and exact time of death in the study population, several sources were used: (1) Iranian electronic death registration system (18); (2) health portal related to the Ministry of Health and Medical Education of Iran; (3) databank related to cemetery organization; (4) portal of the Authority Registration Office of Iran; (5) following the participants via their family physicians; and (6) contacting their family with phone numbers available in regional healthcare centers.

The research was approved by the Ethics Committee of Babol University of Medical Sciences with the approval code MUBABOL.REC.1394.54.

Statistical analysis was performed using the SPSS 17 software package. We used the Kaplan-Meier estimate and the log-rank test (to compare survival rate in different groups) for survival analysis. The proportional hazards assumption was visually checked using the log minus log plot. The cox proportional hazards regression model was used for multivariate survival analysis. Moreover, crude and adjusted hazard ratios with 95\% confidence interval were calculated. Since a specific value was not assumed as an effect measure, two-sided significance was considered, by default. P value less than 0.05 was considered significant.

\section{Results}

In this study, 1562 older adults [863 (55.2\%) males and 699 (44.8\%) females] with the mean age of $69.3 \pm 7.4$ years were assessed. The mean age was $69.9 \pm 7.6$ years for men and $68.6 \pm 6.9$ years for women $(\mathrm{P}<0.001)$. Moreover, of the population, one thousand (64.0\%) were illiterate, 457 (29.3\%) had primary or secondary school education, and 105 (6.7\%) had high school or college education. The mean number of self-reported chronic diseases was $2.72 \pm 1.94$.

The MetS prevalence based on the four mentioned diagnostic criteria and frequency of MetS components is presented in Table 2. As shown, 71.9\% of older adults, including $89.8 \%$ of women and $57.4 \%$ of men, had MetS based on 2005 ATP III diagnostic criteria. Furthermore, based on Iranian, IDF and 2001 ATP III diagnostic criteria, 74.3\%, 68.8\% and $66.7 \%$ of older adults had MetS, respectively.

The mean and standard deviation of MetS components including systolic and diastolic blood pressure, fasting plasma glucose, serum triglyceride, serum HDL cholesterol and waist circumference were $142.7 \pm 22.2 \mathrm{mmHg}, 81.5$ $\pm 11.9 \mathrm{mmHg}, 118.0 \pm 45.7 \mathrm{mg} / \mathrm{dL}, 160.2 \pm 84.0 \mathrm{mg} / \mathrm{dL}, 38.7$ $\pm 4.4 \mathrm{mg} / \mathrm{dL}$ and $95.7 \pm 10.5 \mathrm{~cm}$, respectively.

None of the participants was lost to detect their vital or death status. The flowchart of the participants is presented in Figure 1. Moreover, the five-year survival rate of older adults with and without MetS and its components based on the four diagnostic criteria is presented in Table 3. This table shows that neither MetS (with any of the four mentioned diagnostic criteria) nor its components, except raised fasting plasma glucose $(\mathrm{P}<0.05)$, had significant association with the five-year survival rate of older adults $(\mathrm{P}$ $>0.05)$. The mean survival time of older adults with and without MetS was 56 - 57 months. In addition, 88\% - 89\% of older adults with MetS and $87 \%-90 \%$ of individuals without MetS were alive in five-year follow-up.

The crude and adjusted hazard ratio of MetS and its components was assessed on the five-year survival rate of older adults using the cox proportional hazards regression model by considering age, gender and number of chronic diseases. The results are presented in Table 4 . The table shows that only FBS had a significant crude hazard ratio. However, after adjusting age, gender and number of chronic diseases, MetS significantly decreased the survival rate of older adults $(\mathrm{HR}=1.67 ; 95 \% \mathrm{CI}: 1.16-2.41, \mathrm{P}=0.006)$. 


\begin{tabular}{|c|c|c|c|c|}
\hline Variable & Male, No. (\%) & Female, No. (\%) & Total Number (\%) & P Value \\
\hline MetS based on ATP III 2005 & $495(57.4)$ & $628(89.8)$ & $1123(71.9)$ & $<0.001$ \\
\hline MetS based on ATP III 2001 & $430(49.8)$ & $612(87.6)$ & $1042(66.7)$ & $<0.001$ \\
\hline MetS based on IDF & $439(50.9)$ & $636(91.0)$ & $1075(68.8)$ & $<0.001$ \\
\hline MetS based on Iranian definition & $561(65.0)$ & $599(85.7)$ & $1160(74.3)$ & $<0.001$ \\
\hline Raised blood pressure & $682(79.0)$ & $582(83.3)$ & $1264(80.9)$ & 0.034 \\
\hline Raised serum triglyceride level & $382(44.3)$ & $445(63.7)$ & $827(52.9)$ & $<0.001$ \\
\hline FPG $\geq 100 \mathrm{mg} / \mathrm{dL}$ & $467(54.1)$ & $453(64.8)$ & $920(58.9)$ & $<0.001$ \\
\hline FPG $\geq 110 \mathrm{mg} / \mathrm{dL}$ & $287(33.3)$ & $326(46.6)$ & $613(39.2)$ & $<0.001$ \\
\hline Reduced HDL cholesterol & $633(73.3)$ & $684(97.9)$ & $1317(84.3)$ & $<0.001$ \\
\hline WC $\geq 95 \mathrm{~cm}$ (for Iranian definition) & $475(55.0)$ & $413(59.1)$ & $888(56.9)$ & 0.109 \\
\hline WC for male $\geq 102 \mathrm{~cm}$ and female $\geq 88 \mathrm{~cm}$ (for ATP III definition) & $233(27.0)$ & $563(80.5)$ & $796(51.0)$ & $<0.001$ \\
\hline WC for male $\geq 94 \mathrm{~cm}$ and female $\geq 80 \mathrm{~cm}$ (for IDF definition) & $503(58.3)$ & $661(94.6)$ & $1164(74.5)$ & $<0.001$ \\
\hline
\end{tabular}

Abbreviations: FPG, fasting plasma glucose; HDL, high-density lipoprotein; WC, waist circumference.

${ }^{\mathrm{a}}$ The four diagnostic criteria included: Iranian definition; International Diabetes Federation definition; 2001 Adult Treatment Panel III and 2005 Adult Treatment Panel III

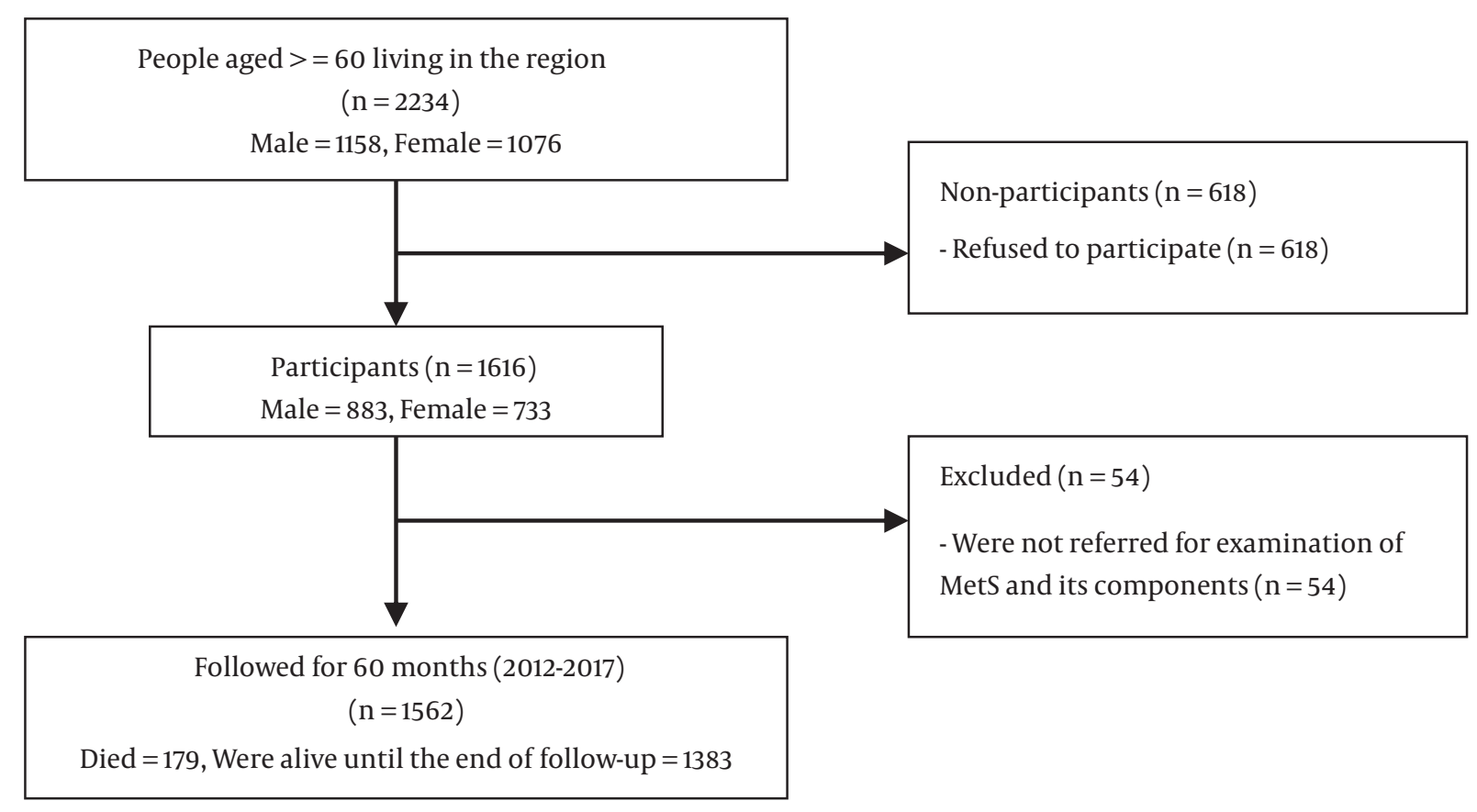

Figure 1. The flowchart of the participants

All MetS components (based on 2005 ATP III) together with age, gender and number of chronic diseases have been considered in the cox proportional hazards regression model. Results showed that only FBS $\geq 100$ had significant association with the survival rate (HR $=1.90 ; 95 \%$ CI: 1.36 - 2.65, P < 0.001) and other variables [raised blood pressure ( $\mathrm{HR}=1.10$; 95\% CI: $0.73-1.67 ; \mathrm{P}=0.642)$, including raised serum triglyceride level $(\mathrm{HR}=1.14 ; 95 \% \mathrm{CI}$ : 0.83 - 1.56; $\mathrm{P}=0.420)$, reduced HDL cholesterol $(\mathrm{HR}=1.01 ; 95 \% \mathrm{CI}$ : 0.68 $1.52 ; \mathrm{P}=0.958)$, and waist circumference $(\mathrm{HR}=1.07 ; 95 \% \mathrm{CI}$ : $0.75-1.51 ; \mathrm{P}=0.731$ ) did not have significant effect on survival rate. 


\begin{tabular}{|c|c|c|c|c|c|}
\hline \multirow{2}{*}{ Variables } & \multicolumn{2}{|c|}{ Five-Year Survival Rate (Percent \pm SE) } & \multicolumn{2}{|c|}{ Mean Survival Time (Month \pm SE) } & \multirow{2}{*}{ P Value (Log-Rank) } \\
\hline & With This Variable & Without This Variable & With This Variable & Without This Variable & \\
\hline MetS based on ATP III 2005 & $88.0 \pm 1.0$ & $90.0 \pm 1.4$ & $56.7 \pm 0.3$ & $56.8 \pm 0.5$ & 0.286 \\
\hline MetS based on ATP III 2001 & $88.2 \pm 1.0$ & $89.2 \pm 1.4$ & $56.8 \pm 0.3$ & $56.7 \pm 0.5$ & 0.568 \\
\hline MetS based on IDF & $89.3 \pm 0.9$ & $86.9 \pm 1.5$ & $57.1 \pm 0.3$ & $56.0 \pm 0.5$ & 0.147 \\
\hline $\begin{array}{l}\text { MetS based on Iranian } \\
\text { definition }\end{array}$ & $87.9 \pm 1.0$ & $90.3 \pm 1.0$ & $57.0 \pm 0.5$ & $56.8 \pm 0.3$ & 0.216 \\
\hline Raised blood pressure & $88.0 \pm 0.9$ & $90.9 \pm 1.7$ & $56.6 \pm 0.3$ & $57.3 \pm 0.5$ & 0.154 \\
\hline $\begin{array}{l}\text { Raised serum triglyceride } \\
\text { level }\end{array}$ & $88.5 \pm 1.1$ & $88.6 \pm 1.2$ & $56.9 \pm 0.4$ & $56.6 \pm 0.4$ & 0.995 \\
\hline FPG $\geq 100 \mathrm{mg} / \mathrm{dL}$ & $86.4 \pm 1.1$ & $91.6 \pm 1.1$ & $56.2 \pm 0.4$ & $57.6 \pm 0.4$ & 0.002 \\
\hline FPG $\geq 110 \mathrm{mg} / \mathrm{dL}$ & $84.5 \pm 1.5$ & $91.1 \pm 0.9$ & $57.5 \pm 0.3$ & $55.6 \pm 0.5$ & $<0.001$ \\
\hline Reduced HDL cholesterol & $88.8 \pm 0.9$ & $86.9 \pm 2.2$ & $56.8 \pm 0.3$ & $56.3 \pm 0.7$ & 0.397 \\
\hline $\begin{array}{l}\text { WC } \geq 95 \mathrm{~cm} \text { (for Iranian } \\
\text { definition) }\end{array}$ & $89.4 \pm 1.0$ & $87.4 \pm 1.3$ & $57.2 \pm 0.3$ & $56.2 \pm 0.5$ & 0.195 \\
\hline $\begin{array}{l}\text { WC for male } \geq 102 \mathrm{~cm} \text { and } \\
\text { female } \geq 88 \mathrm{~cm} \text { (for ATP III } \\
\text { definition) }\end{array}$ & $89.4 \pm 1.1$ & $87.6 \pm 1.2$ & $57.2 \pm 0.3$ & $56.3 \pm 0.4$ & 0.239 \\
\hline $\begin{array}{l}\text { WC for male } \geq 94 \mathrm{~cm} \text { and } \\
\text { female } \geq 80 \mathrm{~cm} \text { (for IDF } \\
\text { definition) }\end{array}$ & $89.4 \pm 0.9$ & $85.9 \pm 1.7$ & $57.1 \pm 0.3$ & $55.8 \pm 0.6$ & 0.054 \\
\hline
\end{tabular}

Abbreviations: FPG, fasting plasma glucose; HDL, high-density lipoprotein; WC, waist circumference.

\begin{tabular}{|c|c|c|c|c|}
\hline Variables & Crude Mortality Hazard Ratio (95\% CI) & PValue & $\begin{array}{l}\text { Adjusted Mortality Hazard Ratio by Age, } \\
\text { Gender and Number of Chronic Diseases } \\
(\text { (95\% CI) }\end{array}$ & PValue \\
\hline MetS based on ATP III (2005) & $1.20(0.86-1.69)$ & 0.287 & $1.67(1.16-2.41)$ & 0.006 \\
\hline MetS based on ATP III (2001) & $1.10(0.80-1.50)$ & 0.568 & $1.48(1.04-2.09)$ & 0.028 \\
\hline MetS based on IDF & $0.80(0.59-1.08)$ & 0.148 & $1.09(0.78-1.54)$ & 0.609 \\
\hline MetS based on Iranian definition & $1.25(0.88-1.78)$ & 0.216 & $1.63(1.13-2.36)$ & 0.010 \\
\hline Raised blood pressure & $1.35(0.89-2.02)$ & 0.156 & $1.14(0.75-1.71)$ & 0.548 \\
\hline Raised serum triglyceride level & $1.00(0.75-1.34)$ & 0.995 & $1.29(0.95-1.75)$ & 0.107 \\
\hline $\mathrm{FPG} \geq 100 \mathrm{mg} / \mathrm{dL}$ & $1.66(1.20-2.28)$ & 0.002 & $1.96(1.42-2.71)$ & $<0.001$ \\
\hline FPG $\geq 110 \mathrm{mg} / \mathrm{dL}$ & $1.81(1.35-2.43)$ & $<0.001$ & $2.05(1.51-2.78)$ & $<0.001$ \\
\hline Reduced HDL cholesterol & $0.85(0.58-1.24)$ & 0.398 & $0.97(0.68-1.37)$ & 0.863 \\
\hline$W C \geq 95 \mathrm{~cm}$ (for Iranian definition) & $0.82(0.61-1.10)$ & 0.195 & $0.92(0.68-1.24)$ & 0.570 \\
\hline $\begin{array}{l}\text { WC for male } \geq 102 \mathrm{~cm} \text {, and female } \geq 88 \\
\mathrm{~cm} \text { (for ATP III definition) }\end{array}$ & $0.84(0.68-1.12)$ & 0.239 & $1.19(0.84-1.69)$ & 0.328 \\
\hline $\begin{array}{l}\text { WC for male } \geq 94 \mathrm{~cm}, \text { and female } \geq 80 \mathrm{~cm} \\
\text { (for IDF definition) }\end{array}$ & $0.73(0.54-1.01)$ & 0.055 & $0.97(0.68-1.37)$ & 0.863 \\
\hline
\end{tabular}

Abbreviations: FPG, fasting plasma glucose; HDL, high-density lipoprotein; WC, waist circumference.

\section{Discussion}

The results showed that most of older adults had MetS that could decrease the five-year survival rate of this population.
Some previous studies presented MetS as the most potentially modifiable risk factor for cardiovascular and cerebrovascular diseases $(11,19)$, which can increase mortality rate in older adults. Moreover, $24 \%$ increased risk of cardio- 
vascular mortality and $23 \%$ increased risk of all-cause mortality have been reported among older adults with MetS, as compared to those without this syndrome (6). Khosravi et al. showed that patients with MetS who had both raised blood pressure and fasting plasma glucose had a high incidence of myocardial infarction, cerebrovascular accident and mortality (10).

MetS itself was associated with reduction in the fiveyear survival of older adults. Contrary to our study, Chiang et al. showed that MetS had survival benefits in older men aged 75 and over in Taiwan, even after adjusting for age, diabetes mellitus, serum cholesterol, and triglyceride (5). Rachas et al. represented MetS components, but not MetS itself, for risk prediction of coronary heart disease (20). Considering that MetS is associated with diabetes mellitus (21) and cardiovascular complications (20), the effect of MetS on increased mortality rate can be justified.

In our research, only fasting plasma glucose $\geq 100$ $\mathrm{mg} / \mathrm{dL}$ out of MetS components had significant negative effect on the survival rate of older adults. Similar to our result, Chiang et al. reported that among different components of MetS, raised fasting plasma glucose had the greatest negative effect on survival (5). Rodriguez-Colon et al. revealed that increasing the number of MetS components caused to elevate the risk for incident stroke. People with raised blood pressure or fasting plasma glucose had higher risk for incident cerebrovascular accidents than patients with MetS without these two components (22). Hess et al. in their research reported that MetS was independently associated with a 70\% elevation in the risk for sudden cardiac death (19). In another study, Krakauer et al. showed that hyperglycemia, hypertension, and low HDL made the greatest association of MetS with mortality hazard ratio (23). A cohort study with 20 years follow-up showed that patients with MetS and impaired blood glucose had the highest mortality rate in comparison with those who did not have MetS or hyperglycemia (24). Another prospective study represented that during 5-year follow-up, patients with MetS had significantly higher cardiovascular mortality and mortality risk was mostly attributed to hyperglycemia (25). An increase in all-cause mortality can be attributed to hyperglycemia and diabetes mainly because of increased cardiovascular deaths (26).

In our research, MetS components exposed older adults to higher mortality hazard. Therefore, an integrated health program is recommended to screen these components, especially hyperglycemia, and also to explore their cardiovascular and metabolic risk factors. Of course, proper health-promoting intervention including lifestyle modification, pharmacologic or non-pharmacological treatment programs can have beneficial impacts on the quality of life of older people and also on reduced mortality and morbidity among them.

The present study is notable for its large sample size, longitudinal study design, and including four diagnostic criteria for MetS definition. However, we did not follow the cause of death, which is an important limitation of the study. In addition, we followed the participants for five years. Of course, a longer follow-up of the study population can more precisely clarify long-term effects of MetS on survival of the elderly.

\subsection{Conclusions}

MetS and one of its components, high FPG, have significant associations with survival of older adults.

\section{Acknowledgments}

Hereby, the financial support of the Vice-Chancellor for Research and Technology of Babol University of Medical Sciences and the cooperation of older adults who participated in the study are greatly appreciated.

\section{Footnotes}

Authors' Contribution: Ali Bijani: substantial contributions to conception and design, acquisition of data, analysis and interpretation of data, final approval of the version to be published. Seyed Reza Hosseini: substantial contributions to conception and design, acquisition of data, and interpretation of data, revising the article critically for important intellectual content, final approval of the version to be published. Reza Ghadimi: substantial contributions to conception and design as well as acquisition of data, revising the article critically for important intellectual content, final approval of the version to be published. Simin Mouodi: drafting the article or revising it critically for important intellectual content, final approval of the version to be published.

Conflict of Interests: The authors declare that there is no conflict of interests.

Ethical Approval: This research was approved by the Ethics Committee of Babol University of Medical Sciences with the approval code MUBABOL.REC.1394.54.

Funding/Support: Babol University of Medical Sciences supported this study. 


\section{References}

1. Saklayen MG. The global epidemic of the metabolic syndrome. Curr Hypertens Rep. 2018;20(2):12. doi: 10.1007/s11906-018-0812-z. [PubMed: 29480368]. [PubMed Central: PMC5866840].

2. Shin D, Kongpakpaisarn K, Bohra C. Trends in the prevalence of metabolic syndrome and its components in the United States 20072014. Int J Cardiol. 2018;259:216-9. doi: 10.1016/j.ijcard.2018.01.139. [PubMed: 29472026].

3. Esposito RC, de Medeiros PJ, Silva FS, Oliveira AG, Soares Aragao $\mathrm{CF}$, Oliveira Rocha HA, et al. Prevalence of the metabolic syndrome according to different criteria in the male population during the Blue November Campaign in Natal, RN, Northeastern Brazil. Diabetes Metab Syndr Obes. 2018;11:401-8. doi: 10.2147/DMSO.S168430. [PubMed: 30122967]. [PubMed Central: PMC6084070]

4. Van Ancum JM, Jonkman NH, van Schoor NM, Tressel E, Meskers CGM, Pijnappels M, et al. Predictors of metabolic syndrome in community-dwelling older adults. PLoS One. 2018;13(10). e0206424. doi: 10.1371/journal.pone.0206424. [PubMed: 30379967]. [PubMed Central: PMC6209297].

5. Chiang PH, Liu CL, Lin MH, Peng LN, Chen LK, Chen JD, et al. Survival benefits of metabolic syndrome among older men aged 75 years and over in Taiwan. J Nutr Health Aging. 2012;16(6):520-4. doi: 10.1007/s12603-011-0344-6. [PubMed: 22659989].

6. Ju SY, Lee JY, Kim DH. Association of metabolic syndrome and its components with all-cause and cardiovascular mortality in the elderly: A meta-analysis of prospective cohort studies. Medicine (Baltimore). 2017;96(45). e8491. doi: 10.1097/MD.0000000000008491. [PubMed: 29137039]. [PubMed Central: PMC5690732].

7. Mazloomzadeh S, Rashidi Khazaghi Z, Mousavinasab N. The prevalence of metabolic syndrome in Iran: A systematic review and metaanalysis. Iran J Public Health. 2018;47(4):473-80. [PubMed: 29900131]. [PubMed Central: PMC5996331].

8. Dalvand S, Niksima SH, Meshkani R, Ghanei Gheshlagh R, SadeghNejadi $S$, Kooti W, et al. Prevalence of metabolic syndrome among Iranian population: A systematic review and meta-analysis. Iran J Public Health. 2017;46(4):456-67. [PubMed: 28540261]. [PubMed Central: PMC5439034].

9. Hajian-Tilaki K. Metabolic syndrome and its associated risk factors in Iranian adults: A systematic review. Caspian J Intern Med. 2015;6(2):5161. [PubMed: 26221500]. [PubMed Central: PMC4478451].

10. Khosravi A, Sadeghi M, Barghikar M. Which components of metabolic syndrome have a greater effect on mortality, CVA and myocardial infarction, hyperglycemia, high blood pressure or both? Adv Biomed Res. 2017;6:121. doi: 10.4103/abr.abr_249_16. [PubMed: 28989914]. [PubMed Central: PMC5627565].

11. Fernandez-Mendoza J, He F, LaGrotte C, Vgontzas AN, Liao D, Bixler EO. Impact of the metabolic syndrome on mortality is modified by objective short sleep duration. J Am Heart Assoc. 2017;6(5). doi: 10.1161/JAHA.117.005479. [PubMed: 28515112]. [PubMed Central: PMC5524093].

12. Hosseini SR, Cumming RG, Kheirkhah F, Nooreddini H, Baiani M, Mikaniki E, et al. Cohort profile: The Amirkola Health and Ageing Project (AHAP). Int J Epidemiol. 2014;43(5):1393-400. doi: 10.1093/ije/dyt089. [PubMed: 23918798].

13. Bijani A, Ghadimi R, Mikaniki E, Kheirkhah F, Mozaffarpur SA, Motallebnejad M, et al. Cohort profile update: The Amirkola Health and Ageing Project (AHAP). Caspian J Intern Med. 2017;8(3):205-12. doi: 10.22088/cjim.8.3.205. [PubMed: 28932373]. [PubMed Central: PMC5596192].
14. Azizi F, Hadaegh F, Khalili D, Esteghamati A, Hossein PF, Delavari A et al. Appropriate definition of metabolic syndrome among Iranian adults: Report of the Iranian National Committee of Obesity. Arch Iran Med. 2010;13(5):426-8.

15. Alberti KG, Zimmet P, Shaw J. Metabolic syndrome-a new worldwide definition. A Consensus Statement from the International Diabetes Federation. Diabet Med. 2006;23(5):469-80. doi: 10.1111/j.14645491.2006.01858.x. [PubMed: 16681555].

16. National Cholesterol Education Program Expert Panel on Detection Evaluation Treatment of High Blood Cholesterol in Adults. Third report of the national cholesterol education program (NCEP) expert panel on detection, evaluation, and treatment of high blood cholesterol in adults (adult treatment panel III) final report. Circulation. 2002;106(25):3143-421. [PubMed: 12485966].

17. Persell SD, Lloyd-Jones DM, Baker DW. Implications of changing national cholesterol education program goals for the treatment and control of hypercholesterolemia. J Gen Intern Med. 2006;21(2):171-6. doi: 10.1111/j.1525-1497.2006.00323.x. [PubMed: 16390501]. [PubMed Central: PMC1484657].

18. Mirabootalebi N, Mahboobi H, Khorgoei T. Electronic death registration system (EDRS) in Iran. Electron Phys. 2011;3:416-8.

19. Hess PL, Al-Khalidi HR, Friedman DJ, Mulder H, Kucharska-Newton A Rosamond WR, et al. The metabolic syndrome and risk of sudden cardiac death: The atherosclerosis risk in communities study. J Am Heart Assoc. 2017;6(8). doi: 10.1161/JAHA.117.006103. [PubMed: 28835363]. [PubMed Central: PMC5586451].

20. Rachas A, Raffaitin C, Barberger-Gateau P, Helmer C, Ritchie K, Tzourio $\mathrm{C}$, et al. Clinical usefulness of the metabolic syndrome for the risk of coronary heart disease does not exceed the sum of its individual components in older men and women. The Three-City (3C) Study. Heart. 2012;98(8):650-5. doi: 10.1136/heartjnl-2011-301185. [PubMed 22505463]. [PubMed Central: PMC3328398].

21. Bijani A, Cumming RG, Hosseini SR, Yazdanpour M, Rahimi M, Sahebian A, et al. Obesity paradox on the survival of elderly patients with diabetes: An AHAP-based study. J Diabetes Metab Disord. 2018;17(1):4551. doi: 10.1007/s40200-018-0337-7. [PubMed: 30288385]. [PubMed Central: PMC6154521].

22. Rodriguez-Colon SM, Mo J, Duan Y, Liu J, Caulfield JE, Jin X, et al. Metabolic syndrome clusters and the risk of incident stroke: The atherosclerosis risk in communities (ARIC) study. Stroke 2009;40(1):200-5. doi: 10.1161/STROKEAHA.108.523035. [PubMed: 18927451].

23. Krakauer NY, Krakauer JC. Anthropometrics, metabolic syndrome, and mortality hazard. J Obes. 2018;2018:9241904. doi 10.1155/2018/9241904. [PubMed: 30123583]. [PubMed Central: PMC6079473].

24. Younis A, Goldkorn R, Goldenberg I, Geva D, Tzur B, Mazu A, et al. Impaired fasting glucose is the major determinant of the 20-year mortality risk associated with metabolic syndrome in nondiabetic patients with stable coronary artery disease. J Am Heart Assoc. 2017;6(11). doi: 10.1161/JAHA.117.006609. [PubMed: 29079562]. [PubMed Central: PMC5721758].

25. Mayer OJ, Bruthans J, Seidlerova J, Karnosova P, Vanek J, Hronova M, et al. Prospective study of metabolic syndrome as a mortality marker in chronic coronary heart disease patients. Eur J Intern Med. 2018;47:5561. doi: 10.1016/j.ejim.2017.07.018. [PubMed: 28755847].

26. Yu OH, Suissa S. Identifying causes for excess mortality in patients with diabetes: Closer but not there yet. Diabetes Care. 2016;39(11):18513. doi: 10.2337/dci16-0026. [PubMed: 27926885]. 